\title{
Rupture of the Tricuspid Valve due to Smashing the Chest into the Steering Wheel
}

\author{
Koray Aykut, MD, ${ }^{1}$ Murat Kaya, MD, ${ }^{2}$ and Unal Acıkel, MD ${ }^{1}$
}

\begin{abstract}
A 32-year-old man was urgently referred to our hospital with severe tricuspid insufficiency following a car accident. The completely flail anterior leaflet, due to the rupture of the papillary muscles, was revealed by a two-dimensional transthoracic echocardiography. In the operation, we also detected a tear on the anterior leaflet and the rupture of numerous chordae tendineae of the other leaflets. Valve repair was not considered feasible, therefore the tricuspid valve was replaced with a $31 \mathrm{~mm}$ mechanical prosthesis. The patient's recovery from surgery was uneventful, and he was discharged on the seventh postoperative day.
\end{abstract}

Keywords: cardiac injury, tricuspid valve, tricuspid insufficiency

\section{Introduction}

Unfortunately, with the increase in the number of vehicles, traffic accidents have become a serious health problem. Cardiac injuries following chest trauma vary from simple myocardial contusions to severe damage to the intracardiac structures. Traumatic tricuspid valve insufficiency is a rare clinical entity. ${ }^{1)}$ We present a patient who developed tricuspid insufficiency following blunt chest trauma.

\section{Case Report}

A traffic accident in August 2011 left a 48-yearold man with thoracic and abdominal trauma, due to his chest hitting the steering wheel. Unfortunately, he was not wearing a seat belt. He was admitted to the state hospital. There, he underwent an urgent splenectomy because of massive bleeding due to splenic rupture. Also, a chest tube was inserted to treat a left-side

${ }^{1}$ Department of Cardiovascular Surgery, Ozel Ege Hospital, Denizli, Turkey

${ }^{2}$ Department of Cardiology, Ozel Ege Hospital, Denizli, Turkey

Received: December 5, 2011; Accepted: April 13, 2012

Corresponding author: Koray Aykut, MD. Ozel Ege Hastanesi, Sirakapılar mahallesi, 495 sokak, Denizli/Turkey

Email: drkaykut@hotmail.com

(C)2012 The Editorial Committee of Annals of Thoracic and Cardiovascular Surgery. All rights reserved. hemopneumothorax. On the fifteenth day following the accident, he was discharged from the hospital. A few weeks later, he was referred to our hospital with complaints of palpitation, dyspnea on effort, and fatigue. A physical examination revealed hepatomegaly, distention of the juguler veins, peripheral edema and a $3-4 / 6$ systolic murmur on the left lateral sternal border. The cardiac silhouette was enlarged with a chest X-ray. A two-dimensional transthoracic echocardiography showed dilatation of the right atrium (approximately $6.5 \mathrm{~cm}$ ), and severe tricuspid regurgitation due to papillary muscle rupture (Fig. 1). Coronary angiography revealed normal coronary arteries. On the basis of these findings, the patient was taken to surgery.

A cardiopulmonary bypass was performed using aortic and bicaval cannulation. Moderate systemic hypothermia, topical cooling and antegrade cold blood cardioplegia were used for myocardial protection. After the midsternotomy and pericardiotomy, a large amount of haemorrhagic pericardial effusion was evacuated.

When the right atrium was opened, the anterior and the posterior papillary muscles were found to be ruptured (Fig. 2). In addition to numerous ruptured chordae tendineae, there was a tear on the anterior leaflet.

Valve repair was not suitable for this case, therefore the tricuspid valve was replaced with a $31 \mathrm{~mm}$ mechanical prosthesis. A temporary epicardial pacemaker wire was inserted. Sinus rhythm spontaneously resumed. The 


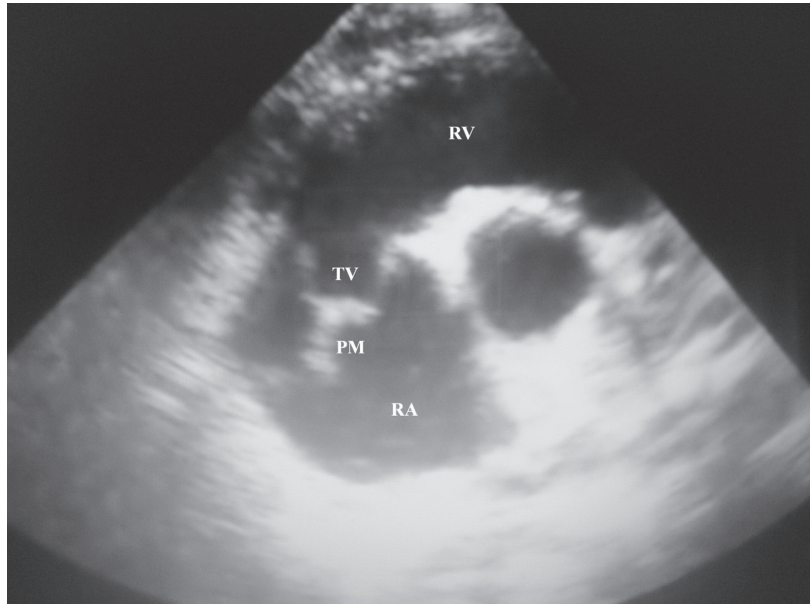

Fig. 1 Preoperative transthoracic echocardiographic view showing flail leaflets of the tricuspid valve and ruptured papillary muscle in the right atrium during the systolic phase. RV: right ventricule; TV: tricuspid valve; PM: papillary muscle; RA: right atrium

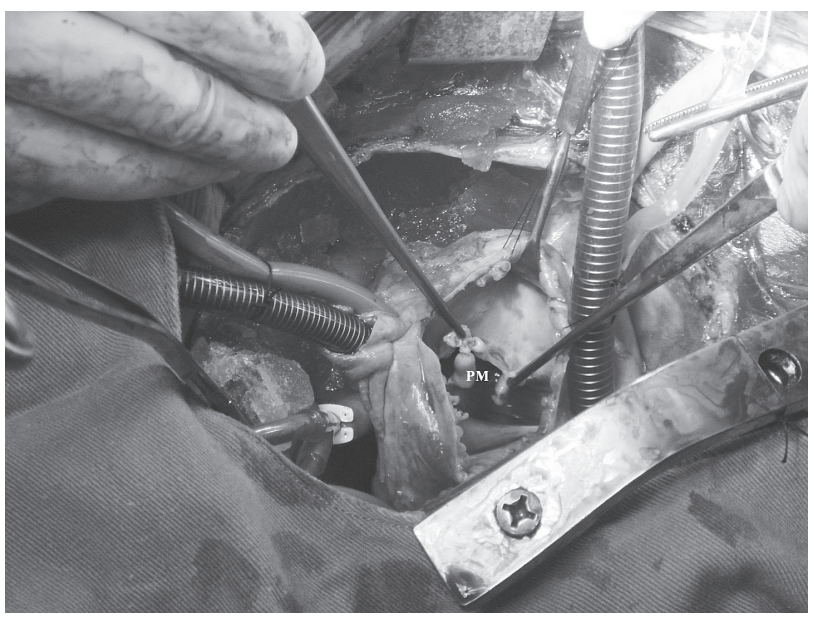

Fig. 2 Intraoperative view showing the avulsed papillary muscle head and the flail anterior leaflet of the tricuspid valve. PM: papillary muscle

postoperative period was without complication, and the patient was discharged after a week.

\section{Discussion}

Blunt chest trauma is frequently seen due to the increase in the number of traffic vehicles. Several types of injuries to the heart have been described. Injuries of the cardiac valves as a result of blunt chest trauma are relatively rare.

The right ventricle is situated just behind the sternum. Therefore, it has a predisposition for an anteroposterior compression injury. A sudden increase in right ventricle pressure during the end diastolic phase causes serious traction on both the valvular and subvalvular apparatus.

Traumatic tricuspid insufficiency may be easily tolerated for a long time, but sometimes it requires urgent intervention. ${ }^{2)}$ The clinical presentation depends on the type of injury. Subvalvular apparatus injuries, such as the rupture of papillary muscles and chordae tendineae, become symptomatic rapidly.

Usually, the anterior papillary muscle is damaged following blunt cardiac trauma. ${ }^{3)}$ Valvular damage, for example, a torn leaflet, may have a delayed onset of symptoms. In our case, in addition to numerous chordae tendineae ruptures and a tear on the anterior leaflet, both papillary muscles were ruptured.

Valve repair should be the first choice for surgical treatment to preserve the function of the right ventricle. ${ }^{4,5)}$ Chordal replacement, leaflet resuture or suspension with annuloplasty are widely used techniques for tricuspid valve repair. However, in rare conditions such as that of our patient, valve repair is not feasible.

In such patients, valve replacement becomes unavoidable. Both xenografts and mechanical valves are suitable for tricuspid valve replacement. Xenografts are usually preferred to mechanical valves, because they have good long-term durability and a low incidence of complications in the tricuspid position. ${ }^{6}$ )

Thus, physicians should be aware of cardiac valve lesions following chest trauma, due to the fact that tricuspid valve lesions may sometimes have an insidious onset of symptoms. The results of surgery for tricuspid valve are excellent if the operation is performed before the right ventricle function deteriorates. All patients sustaining major chest trauma should undergo echocardiographic follow-up and should be advised to return to the hospital if symptoms of palpitation, dyspnea on effort or fatigue become evident.

\section{References}

1) Krasna MJ, Flancbaum L. Blunt cardiac trauma: clinical manifestations and management. Semin Thorac Cardiovasc Surg 1992; 4: 195-202.

2) Katz NM, Pallas RS. Traumatic rupture of the tricuspid valve: repair by chordal replacements and annuloplasty. J Thorac Cardiovasc Surg 1986; 91: 310-4.

3) Bertrand S, Laquay N, El Rassi I, et al. Tricuspid insufficiency after blunt chest trauma in a nineyear-old child. Eur J Cardiothorac Surg 1999; 16: 587-9. 
4) Noera G, Sanguinetti M, Pensa P, et al. Tricuspid valve incompetence caused by nonpenetrating thoracic trauma. Ann Thorac Surg 1991; 51: 320-2.

5) Bolton JW. Traumatic tricuspid valve injury: leaflet resuspension repair. Ann Thorac Surg 1996; 61: 721-2.
6) Guerra F, Bortolotti U, Thiene G, et al. Long-term performance of the Hancock porcine bioprosthesis in the tricuspid position. A review of forty-five patients with fourteen-year follow-up. J Thorac Cardiovasc Surg 1990; 99: 838-45. 